\title{
Morbidity of caesarean delivery: a comparative study between early and advanced stages of labour in an Indian tertiary care center
}

\section{Amrutha Ramachandran*, Meera Pavithran, Beena Bahuleyan, Kusumam Vilangot Njalil, Rabiyabi Vethavayal, Umadevi Narayanan}

Department of Obstetrics and Gynaecology, Medical College Kozhikode, Kerala, India

Received: 23 October 2013, Revised: 17 November 2013

Accepted: 21 November 2013

\section{*Correspondence:}

Dr. Amrutha Ramachandran,

E-mail: amrutharamachandran@yahoo.com

(C) 2013 Ramachandran A et al. This is an open-access article distributed under the terms of the Creative Commons Attribution Non-Commercial License, which permits unrestricted non-commercial use, distribution, and reproduction in any medium, provided the original work is properly cited.

\section{ABSTRACT}

Background: The aim was to compare the maternal and perinatal complications associated with caesarean sections performed in the early and advanced stage of labour.

Methods: A retrospective analysis of 131 women with singleton term pregnancies who underwent emergency caesarean section. The study was done in a tertiary care teaching hospital in India. In this study advanced labour was defined as one with cervical dilatation $8 \mathrm{~cm}$ or more at the time of caesarean section. The primary outcome variables were a maternal composite morbidity and a neonatal composite morbidity. Categorical data were compared using chi square test or Fischer's exact test.

Results: 73 women (56\%) underwent caesarean delivery in the early labour and 58(44\%) in advanced labour. 12/73 (16.4\%) patients in early stage of labour had at least one maternal complication (Composite maternal morbidity) compared to $18 / 58(31 \%)$ women who had caesarean in advanced stage $(p=0.048)$. Seven patients out of 73 in the early labour and $14 / 58$ in the advanced labour $(p=0.024)$ had at least one neonatal complication (Composite neonatal morbidity).

Conclusions: The morbidity of primary caesarean sections done in the advanced stage of labour is associated with increased maternal and neonatal morbidity compared to that done in the early stage. A larger study will be needed to establish the inference.

Keywords: Caesarean section, Advanced labour, Maternal morbidity, Maternal mortality, Perinatal morbidity

\section{INTRODUCTION}

Cesarean delivery is associated with an increased risk of postpartum maternal death. ${ }^{1}$ There are several studies which conclude that the length of the second stage of labour influences maternal morbidity, but not the neonatal morbidity. ${ }^{2-6}$ Cheng et $\mathrm{al}^{7}$ in a retrospective study 2007 concluded that both neonatal and maternal morbidity were higher when the length of the second stage of labour was more than 3 hours in multiparous women. This is in contrast to an earlier retrospective study by the same authors in $2004^{5}$ which found that neonatal morbidity was not significantly increased when the length of the second stage was prolonged in nulliparous women. Epidural analgesia was given to the patients in the above studies and could be the reason for conflicting results.

Caesarean sections could be delayed due to several reasons. In a developing country like India, the increased patient load, inadequate prenatal care, a dearth of resources like the lack of adequate number of anesthesiologists, the lack of sufficient number of operation theatres, and the failure to identify the slow 
progress of labour may be some of the reasons for the delay. ${ }^{8}$ This study was prompted by an observation that maternal and neonatal morbidity was probably higher in the patients in whom emergency caesarean section was done at an advanced stage of labour. The purpose of this study was to compare the maternal and perinatal complications associated with caesarean sections performed in the early and advanced stage of labour.

\section{METHODS}

This is a retrospective analysis of 131 women with singleton term pregnancies who underwent emergency caesarean section (CS). The study period was from January 2010 to Dec 2010. The study was carried out in a tertiary academic teaching hospital in Kerala, India. An institutional review board approval was obtained for this study. The clinical records of the mother, the neonate, surgical records and the labour room records were studied. There were a total of 12699 deliveries in 2010 at the institution. Of these $3991(31.5 \%)$ were delivered by caesarean section. 2417(19\%) were primary CS. Among them, 1909 were emergency CS. After applying the inclusion and exclusion criteria 131 consecutive women who underwent CS were recruited for the study. They were divided into two groups- Women in early labour and women in advanced labour. For this study, an advanced labour was defined as the one with cervical dilatation $8 \mathrm{~cm}$ or more at the time of caesarean section. Women in the active phase of labour with gestational age 37-41weeks, singleton pregnancy, and cephalic presentation, with intact membranes or duration of rupture of membranes that is less than three hours at the time of admission were included in the study. Women having severe preeclampsia / eclampsia, multiple pregnancy, gestational diabetes mellitus on insulin, intra uterine growth retardation, non vertex presentations, any significant medical disorders, attempted operative vaginal delivery, post dated pregnancy, ante-partum hemorrhage, meconium stained amniotic fluid, prematurity and those in whom PGE1 (Prostaglandin E1) tablets or Foleys catheter were used for induction, were excluded from the study. Though induction of labour with PGE1 and Foley's catheter was excluded, the induction of labour with PGE2 gel was included. PGE1 as compared to PGE2 is known to produce more fetal distress and Foley's catheter induction could introduce sepsis. This was done to exclude other confounding factors likely to affect the morbidity. A comparison of maternal morbidity and neonatal morbidity was done between the group of women who underwent caesarean section in the early and advanced stage of labour. Maternal morbidity was studied in terms of post partum hemorrhage (estimated blood loss more than $1000 \mathrm{ml}$ ), requirement for blood transfusion, occurrence of uterine lacerations, puerperal infection / fever, wound complications (more than $38^{\circ} \mathrm{C}$ on two or more occasions in any 48 hour period, excluding the first 24 hours after delivery), admission to intensive care unit, need for hysterectomy and maternal mortality. Neonatal morbidity was compared in terms of neonatal asphyxia, sepsis, trauma, intensive care admission and neonatal mortality. The primary outcome variables were a maternal composite (composed of at least one of the above mentioned maternal morbidity) and a neonatal composite (composed of at least one of the above mentioned neonatal morbidity). Categorical data were compared using chi square test or Fischer's exact test as appropriate. A p value less than 0.05 was considered as statistically significant. Statistical analysis was performed with SPSS.17 software.

\section{RESULTS}

131 women were included in the study. The mean age was 23.2 years (range 18-32 years). 117 (89\%) were primi gravida. The maternal characteristics are summarized in Tables 1 and 2. The labor was induced in $79(60 \%)$. The major indications for induction of labour premature rapture of membranes (PROM) in 23 women $(17.6 \%)$, on date induction in 21 women $(16.0 \%)$. The details of indications for induction is given in Table 3 . The labour was augmented with oxytocin infusion in 116 women $(88.5 \%)$. The details of indication of emergency caesarean section is given in Table 4. Arrest of descent was the commonest indication (62 women, $47.4 \%$ ). All except one underwent surgery under spinal anesthesia. 73 women (56\%) underwent caesarean delivery in early labour and 58(44\%) in advanced labour. The mode of delivery was as head first in $123(94 \%)$ and breech first in $8(6 \%)$. In these 8 cases, though the presentation was vertex, the babies were extracted as breech due to advanced labour. Maternal morbidity is summarized in table 5. Puerperal fever was the commonest, seen in 19 patients (14.5\%). The number of patients with at least one maternal morbidity (Composite maternal morbidity) was 30 (22.9\%). 12/73 patients in early labour had at least one maternal complication compared to $18 / 58$ women who had caesarean in advanced labour ( $\mathrm{p}$ value 0.048: Odds Ratio $1.51,95 \%$ CI 1.037 to 2.212 ). When considered independently, none of the complications were significantly different between the groups. The incidence of puerperal fever morbidity was showing an increased trend in women undergoing caesarean section in advanced labour ( $\mathrm{p}$ value 0.073 ). The mean duration of maternal hospital stay was 7.5 days (Range 5 to 27 days). The neonatal morbidity is summarized in Table 6 . Twenty neonates required intensive care admission (15.2\%), 21 neonates (16\%) had any one of the neonatal morbidity (composite neonatal morbidity), $7 / 73$ in $t$ early labour and 14/58 in the advanced labour ( $\mathrm{p}$ value, 0.024: Odds Ratio $1.66,95 \%$ CI 1.141 to 2.435 ). When individual neonatal morbidity was studied, only the incidence of neonatal intensive care unit admission was significantly different between the groups ( $\mathrm{p}$ value $0.043)$. 
Table 1: Maternal characteristics (Continuous variables).

\begin{tabular}{|lll|}
\hline & \multicolumn{2}{l|}{ Caesarean section in } \\
\hline $\begin{array}{l}\text { Maternal } \\
\text { characteristics }\end{array}$ & $\begin{array}{l}\text { early } \\
\text { labour } \\
\text { (mean) }\end{array}$ & $\begin{array}{l}\text { advanced } \\
\text { labour (mean) }\end{array}$ \\
\hline Age (years) & 23.29 & 23.19 \\
\hline $\begin{array}{l}\text { Gestational age at } \\
\text { delivery(weeks) }\end{array}$ & 39.32 & 39.22 \\
\hline $\begin{array}{l}\text { Decision to delivery } \\
\text { interval (minutes) }\end{array}$ & 110.9 & 67.98 \\
\hline $\begin{array}{l}\text { Duration of first stage } \\
\text { (minutes) }\end{array}$ & 425.2 & 445.18 \\
\hline $\begin{array}{l}\text { Maternal hospital stay } \\
\text { (days) }\end{array}$ & 7.2 & 7.9 \\
\hline
\end{tabular}

Table 2: Maternal characteristics (Dichotomous variables).

\begin{tabular}{|c|c|c|c|c|}
\hline \multirow{2}{*}{\multicolumn{2}{|c|}{ Maternal characteristics }} & \multicolumn{3}{|c|}{ Caesarean section in } \\
\hline & & \multirow{2}{*}{$\begin{array}{l}\begin{array}{l}\text { Early } \\
\text { labour } \\
(\%)\end{array} \\
64(87.6)\end{array}$} & \multirow{2}{*}{$\begin{array}{l}\text { Advanced } \\
\text { labour (\%) }\end{array}$} & $\begin{array}{l}\mathrm{p} \\
\text { value }\end{array}$ \\
\hline \multirow[t]{2}{*}{ Gravidity } & Primi & & & \multirow{2}{*}{0.57} \\
\hline & Multi & $9(12.4)$ & $5(8.7)$ & \\
\hline \multirow[t]{2}{*}{ Type of labour } & Induced & $47(64.4)$ & $32(55.1)$ & \multirow{2}{*}{0.36} \\
\hline & Spontaneous & $26(35.6)$ & $26(44.9)$ & \\
\hline \multirow[t]{2}{*}{$\begin{array}{l}\text { Augmentation } \\
\text { of labour }\end{array}$} & Augmented & $63(86.3)$ & 53(91.4) & \multirow{2}{*}{0.41} \\
\hline & $\begin{array}{l}\text { Not } \\
\text { augmented }\end{array}$ & $10(13.7)$ & $5(8.6)$ & \\
\hline \multirow[t]{2}{*}{ Anaesthesia } & Spinal & $73(100)$ & $57(98.3)$ & \multirow{2}{*}{0.44} \\
\hline & General & $0(0)$ & $1(1.7)$ & \\
\hline \multirow[t]{2}{*}{ Duration } & $<90$ minutes & $70(95.9)$ & $58(100)$ & \multirow{2}{*}{0.25} \\
\hline & $>90$ minutes & $3(4.1)$ & $0(0)$ & \\
\hline
\end{tabular}

$\%$ : Percentage
Table 3: Indications for induction of labour.

\begin{tabular}{|lll|}
\hline Indication & $\begin{array}{l}\text { Number of } \\
\text { patients }\end{array}$ & Percent \\
\hline Post dates & 13 & 9.9 \\
\hline PROM & 23 & 17.6 \\
\hline On date & 21 & 16.0 \\
\hline Big baby & 3 & 2.3 \\
\hline BOH & 2 & 1.5 \\
\hline Maternal request & 1 & 0.8 \\
\hline GDM on diet & 3 & 2.3 \\
\hline Abnormal GCT & 21 & 16.0 \\
\hline $\begin{array}{l}\text { Gestational } \\
\text { Hypertension }\end{array}$ & 21 & 16.0 \\
\hline $\begin{array}{l}\text { Decreased foetal } \\
\text { movement }\end{array}$ & 13 & 9.9 \\
\hline Data not available & 10 & 7.6 \\
\hline
\end{tabular}

PROM: Premature Rupture of Membranes

BOH: Bad Obstetric History

GDM: Gestational Diabetes Mellitus

GCT: Glucose Challenge Test

Table 4: Indication for emergency LSCS.

\begin{tabular}{|lll|}
\hline Indication & $\begin{array}{l}\text { Number of } \\
\text { patients }\end{array}$ & Percent \\
\hline $\begin{array}{l}\text { First degree CPD, arrest } \\
\text { of dilatation }\end{array}$ & 4 & 3.1 \\
\hline Arrest of descent & 62 & 47.4 \\
\hline Failure to progress & 23 & 17.5 \\
\hline Arrest of dilatation & 30 & 22.9 \\
\hline $\begin{array}{l}\text { First degree CPD, failed } \\
\text { trial }\end{array}$ & 11 & 8.4 \\
\hline Others & 1 & 0.8 \\
\hline
\end{tabular}

LSCS: Lower Segment Caesarean Section CPD: Cephalo Pelvic Disproportion

Table 5: Univariate analysis for maternal morbidity, LSCS at early labour vs. advanced labour.

\begin{tabular}{|llllll|}
\hline Variable & $\begin{array}{l}\text { Number of } \\
\text { patients }\end{array}$ & Percentage & Early labour & Advanced labour & p value \\
\hline Blood loss $>500 \mathrm{ml}$ & 5 & 3.8 & 1 & 4 & 0.17 \\
\hline Blood transfusion & 3 & 2.3 & 1 & 2 & 0.584 \\
\hline Maternal ICU admission & 6 & 4.6 & 2 & 4 & 0.405 \\
\hline
\end{tabular}




\begin{tabular}{|c|c|c|c|c|c|}
\hline Hysterectomy & 1 & 0.8 & 1 & 0 & 1.000 \\
\hline Intra operative complication & 8 & 6.1 & 3 & 5 & 0.465 \\
\hline Maternal Infection & 22 & 16.8 & 9 & 13 & 0.125 \\
\hline Wound Complication & 16 & 12.2 & 9 & 7 & 0.964 \\
\hline Puerperal fever & 19 & 14.5 & 7 & 12 & 0.073 \\
\hline Maternal mortality & 0 & 0 & & & \\
\hline Readmission to hospital & 0 & 0 & & & \\
\hline
\end{tabular}

LSCS: Lower Segment Caesarean Section ICU: Intensive Care Unit

Table 6: Univariate analysis for neonatal morbidity, LSCS at early labour vs. advanced labour.

\begin{tabular}{|llllll|}
\hline Variable & $\begin{array}{l}\text { Number } \\
\text { of } \\
\text { patients }\end{array}$ & Percentage & $\begin{array}{l}\text { Early } \\
\text { labour }\end{array}$ & $\begin{array}{l}\text { Advanced } \\
\text { labour }\end{array}$ & $\begin{array}{l}\mathbf{p} \\
\text { value }\end{array}$ \\
\hline $\begin{array}{l}\text { Birth } \\
\text { asphyxia }\end{array}$ & 5 & 3.8 & 2 & 3 & 0.655 \\
\hline Sepsis & 9 & 6.8 & 4 & 5 & 0.508 \\
\hline $\begin{array}{l}\text { ICU } \\
\text { admission }\end{array}$ & 20 & 15.2 & 7 & 13 & 0.043 \\
\hline $\begin{array}{l}\text { Neonatal } \\
\text { mortality }\end{array}$ & 1 & 0.8 & 1 & 0 & 1.000 \\
\hline
\end{tabular}

ICU: Intensive Care Unit

LSCS: Lower Segment Caesarean Section

\section{DISCUSSION}

The optimal management of second stage of labour should maximize the probability of vaginal delivery and minimize the risks of maternal and neonatal morbidity as well as death. Maternal morbidity associated with spontaneous vaginal delivery is lower than that of operative delivery in the second stage of labour. ${ }^{2,3}$ But there are few studies comparing the maternal and neonatal morbidities of caesarean sections done in early stages of labour with advanced labour. Certain published reports suggest that caesarean section in the second stage of labour has a higher risk of maternal but not perinatal morbidity. ${ }^{3-6}$

In our study, caesarean delivery in advanced labour was associated with a raised maternal and neonatal morbidity composites when compared to caesarean section in the earlier phase. Certain other studies have similar outcomes. ${ }^{2,9}$ The length of labour is affected by epidural analgesia, ${ }^{10,11}$ maternal age and ethnic differences. ${ }^{12,13}$ The American College of Obstetricians and gynecologists $(\mathrm{ACOG})^{14}$ has defined a prolonged second stage of labour in nulliparous women as the lack of continuing progress for 3 hours with regional anesthesia or 2 hours without regional anesthesia and prolonged second stage of labour in multiparous women was defined as lack of progress for 2 hours with or 1 hour without regional anesthesia. Allen et al in a study from Canada reported that the risks of both maternal and perinatal adverse outcomes rise with increased duration of the second stage, longer than 3 hours in nullipara and longer than 2 hours in multipara. ${ }^{15}$ A systematic review reported that the variable definitions of prolonged second stage of labour, diverse study population characteristics, lack of control of confounding variables increase the difficulty in addressing the duration of second stage to obstetric outcomes. ${ }^{16}$

Caesarean deliveries in developing countries is associated with increased morbidity. ${ }^{17-19}$ There are different reasons for a delay in performing Caesarean sections. In developing countries, increased patient load and lack of resources are important reasons. The present study compares the outcome in a tertiary teaching hospital. This study has the advantage that none of the patients were under epidural analgesia during labour. Epidural analgesia is not routinely performed in our institution. Also a deliberate attempt was made to exclude patients with possible confounding factors likely to affect maternal and neonatal morbidity. The study is limited by its retrospective nature and small sample size.

\section{CONCLUSIONS}

Our study has shown that, the morbidity of primary caesarean sections done in the advanced labour is associated with increased maternal and neonatal morbidity compared to that done in the early labour. This result is evident only when individual morbidity components are grouped together to calculate a composite maternal and neonatal morbidity. Individual components showed no statistically significant difference. A study with larger number of patients will be needed to establish the impact of time of caesarean section on the individual causes of maternal and perinatal morbidity. 


\section{ACKNOWLEDGEMENTS}

The authors wish to express their sincere gratitude to Dr Ajitha BK and Dr Krishnakumar Thankappan for their assistance in the statistical analysis.

\section{Funding: None}

Conflict of interest: None declared

Ethical approval: The study was approved by the Institutional Ethical Committee

\section{REFERENCES}

1. Deneux-Tharaux C, Carmona E, Bouvier-Colle MH, et al Postpartum maternal mortality and cesarean delivery. Obstet Gynecol. 2006; 108: 541-548.

2. Allen VM, O'Connell CM, Baskett TF. Maternal and perinatal morbidity of caesarean delivery at full cervical dilatation compared with caesarean delivery in the first stage of labour. BJOJ 2005; 112: 986990.

3. Alexander JM, Leveno KJ, Rouse DJ et al Comparison of maternal and foetal outcomes from primary caesarean delivery during the second compared with first stage of labour. Obstet Gynecol 2007; 109: 917-921.

4. Sung JF, Daniels KI, Brodzinsky L, El-Sayed YY, Caughey A B, Lyell D J. Caesarean delivery outcomes after a prolonged second stage of labour. Am J Obstet Gynecol 2007; 197:306e1-306e5.

5. Cheng YW, Hopkins LM, Caughey AB How long is too long: Does a prolonged second stage of labour in nulliparous women affect maternal and neonatal outcomes? Am J Obstet Gynecol 2004; 191: 933938.

6. Selo-Ojeme D, Sathiyathasan S, Fayyaz M. Caesarean delivery at full cervical dilatation versus caesarean delivery in the first stage of labour: comparison of maternal and perinatal morbidity. Arch Gynecol Obstet. 2008; 278:245-249.

7. Cheng YW, Hopkins LM, Laros RK Jr, Caughey $\mathrm{AB}$ : Duration of second stage of labour in multiparous women: maternal and neonatal outcomes. Am J Obstet Gynecol 2007; 196:585 e1589 e6.

8. Munnur U, Karnad DR, Bandi VD, Lapsia V, Suresh MS, Ramshesh P, Gardner MA, Longmire S,
Guntupalli KK. Critically ill obstetric patients in an American and an Indian public hospital: comparison of case-mix, organ dysfunction, intensive care requirements, and outcomes. Intensive Care Med. 2005 Aug; 31 (8): 1087-94.

9. Cebekulu L, Buchman EJ. Complications associated with caesarean section in the second stage of labour. Int J Gynecol Obstet 2006; 95:110-114.

10. Albers LL. The duration of labour in healthy women. Perinatol 1999; 19: 114-119.

11. Friedman FA. The graphic analysis of labour. Am J Obstet Gynecol 1954; 68:1568-1575.

12. Greenberg MB, Cheng YW, Sullivan M, Norton ME, Hopkins L M, Caughey AB Does the length of labour vary by maternal age? Am J Obstet Gynecol 2007; 197:428e 1-7.

13. Greenberg MB, Cheng YW, Hopkins LM, Stotland NE, Bryant AS, Caughey AB. Are there ethnic differences in the length of labour? Am J Obstet Gynecol 2006;195: 743-748.

14. American College of Obstetricians and Gynecologists. Operative Vaginal delivery. Washington, DC: The College; 2000. ACOG practice bulletin no. 17 .

15. Allen VM, Baskett TF, O Connell CM, McKeen D, Allen AC. Maternal and perinatal outcomes with increasing duration of second stage of labour .Obstet Gynecol 2009;113:1248-1258.

16. Altman MR, Lydon-Rochelle MT. Prolonged second stage of labour and risk of adverse maternal and perinatal outcomes: a systematic review. Birth 2006;33: 315-322.

17. Shah A, Fawole B, M'imunya JM, Amokrane F, Nafiou I, Wolomby JJ, et al. Cesarean delivery outcomes from the WHO global survey on maternal and perinatal health in Africa. Int $\mathbf{J}$ Gynaecol Obstet. 2009; 107:191-197.

18. McClure EM, Saleem S, Pasha O, Goldenberg RL. Stillbirth in developing countries: a review of causes, risk factors and prevention strategies. J Matern Fetal Neonatal Med. 2009;22:183-190.

19. Wylie BJ, Mirza FG. Cesarean delivery in the developing world. Clin Perinatol. 2008;35:571-582.

DOI: $10.5455 / 2320-1770$. ijrcog20131230

Cite this article as: Ramachandran A, Pavithran M, Bahuleyan B, Njalil KV, Vethavayal R,

Narayanan U. Morbidity of caesarean delivery: a comparative study between early and advanced stages of labour in an Indian tertiary care center. Int J Reprod Contracept Obstet Gynecol 2013;2:64650. 